\title{
TRADUÇÃO
}

\section{A ideia de constituição republicana ${ }^{1}$}

\section{Ernst Cassirer}

Senhoras e senhores!

Quando me foi designada a honorabilíssima tarefa, por parte do Senado de Hamburgo, de falar aos senhores nestas horas festivas, então, manifestou-se nesse pedido, se eu compreendo-o corretamente, uma convicção geral: a convicção de que os grandes problemas histórico-políticos que dominam e movimentam nosso presente não podem ser pura e simplesmente abstraídos das questões mais gerais e fundamentais do espírito, as quais a filosofia sistemática apresenta e procura solucionar no decurso de sua história. Não são duas forças heterogêneas, muito menos inimigas, que aqui se colocam em oposição; mas, afigura-se, em toda parte, uma ação recíproca viva entre o mundo do pensamento e o mundo factual, entre a estrutura das ideias e a estrutura estatal, e a realidade social. "Por meio das oscilações do pêndulo", assim disse Goethe em certa ocasião, "é regido o tempo; por meio do fluxo de mudanças da ideia para a experiência, é regido o mundo moral e científico" (Goethe, 1891, p.354). Desse ininterrupto fluxo de mudanças eu gostaria, para a presente ocasião comemorativa, de escolher uma única fase e procurar apresentá-la diante dos senhores com explícita clareza. Eu desejo discursar sobre o seguinte: a relação entre teoria e prática, como se estabelece no pensamento do direito natural e do direito público do idealismo filosófico alemão. A filosofia do idealismo alemão alcançou sua maturidade e perfeição na obra de Kant - na Crítica da razão pura, publicada em 1781, e na Crítica da razão prática, publicada em 1788. E, pouco tempo depois, em 26 de agosto de 1789, seguiu-se à Constituinte Francesa a declaração dos direitos dos homens e do cidadão, a qual constituía o verdadeiro marco para as forças políticas das quais a Revolução francesa se nutria. Estão esses dois fatos - os quais abrangem em si uma grande mudança histórico-universal - simplesmente próximos no tempo, ou estão eles - seja em que sentido for, mesmo que indiretamente atrelados? Eles seguem isoladamente na sequência dos acontecimentos mundanos, ou estão, em seu sentido interno, na ordenação das ideias, ligados entre si? Quando eu procuro dar uma resposta a essa pergunta, isso não pode e não deve significar que

\footnotetext{
1 Conferência proferida por Cassirer em 11 de Agosto de 1928 nas comemorações à constituição. Publicado originalmente como: Cassirer, E. (1929). Die Idee der republikanischen Verfassung: Rede zur Verfassungsfeier am 11. August 1928. Hamburg: De Gruyter. [(Nota do tradutor (N.T.)]. Tradução de Serzenando Alves Vieira Neto.
} 
eu desejo desenvolver pormenorizadamente diante dos senhores o lugar individual e meramente pessoal de Kant para as ideias políticas fundamentais da Revolução Francesa. ${ }^{2}$ Essa questão da biografia de Kant tem sido examinada diversas vezes e de forma minuciosa, sem esgotar, entretanto, o problema relativo à história das ideias que se encontra diante de nós. Kant, à semelhança de quase todo espectador do grande drama histórico universal que foi a Revolução Francesa, oscilou diversas vezes em seu julgamento dos fatos e acontecimentos particulares. Ele passou por quase toda escala de sentimentos e tendências humanas opostas; da mais elevada admiração e entusiasmo, com as primeiras fases da Revolução, até a mais obstinada rejeição dos atos de violência nos quais ela findou. Somente uma coisa permaneceu sempre igual e inalterada em Kant: o apaixonado interesse pelos desdobramentos da Revolução. Todos os seus biógrafos convergem quando nos narram sobre esse interesse. E nessas narrativas, frequentemente, apresenta-se diante de nós uma imagem de Kant totalmente diferente da que poderíamos pensar em cultivar com base na ideia de um pensador abstrato e estoico, despossuído de afeto. Com o mais profundo e acalorado interesse, Kant dedicou-se, durante os anos da Revolução, aos acontecimentos políticos cotidianos. Era uma época em que ele - como relatam seus biógrafos Borowski e Jachmann - estava tomado por uma verdadeira fome por jornais, mesmo que tivesse que andar milhas de distâncias até a estação postal; uma época em que nada poderia alegrá-lo mais do que uma notícia autêntica de primeira mão. E Kant, também, nunca fugiu ao debate de suas convicções e juízos políticos. "Era uma época em Königsberg", assim nos narra o professor da faculdade de medicina da Universidade de Königsberg, Metzger, ${ }^{3}$

em que qualquer um que não julgasse a Revolução Francesa como algo favorável, mas ousasse relativizar seus resultados, era logo imbuído com o estigma de Jacobino. Kant não se deixava se assustar com isso, discursando nas mais ilustres ocasiões da Revolução, e dava-se muita atenção às suas palavras, um homem geralmente muito estimado, cujos pontos de vista eram tidos como de grande valor (Metzger 1804, p.15-16).

Entretanto, não é nesses detalhes biográficos que devemos imergir se desejarmos compreender a conexão entre o universo de ideias de Kant e o universo de ideias da Revolução Francesa em seu verdadeiro significado e de maneira realmente profunda. Antes, pelo contrário, ergue-se aqui outra questão: a questão de se, e até que ponto, a tendência intelectual fundamental, por meio da qual a filosofia teórica de Kant e sua ética são determinadas, relaciona-se com aquelas tendências das quais emanou o movimento revolucionário na França. Essa pergunta não pode ser respondida se

2 Sobre o posicionamento de Kant em relação à política de sua época ver, por exemplo Vorländer (1912, p.67 em diante). Assim como o artigo Vorländer, 1912. Ver ainda a seguinte exposição sinóptica: Borries, 1928.

3 Ver Vorländer, 1912, p.250. 
nos contentarmos simplesmente em colocar a "Revolução do Pensamento", efetuada por Kant em sua filosofia, ao lado da grande revolução política - devemos retomar as fontes de ambas, a fim de encontrar nestas o ponto, de fato, de sua conjunção.

Que o principal propulsor da Revolução Francesa foi de cunho intelectual, que ela desde os seus primeiros momentos permaneceu sob o domínio de determinada corrente do pensamento e que essa corrente participou de maneira decisiva em cada passo particular dado pela Revolução: isso se põe por toda parte à mostra, de maneira clara e inconfundível. É antes de tudo mérito de Hippolyte Taine, ${ }^{4}$ que, em sua grande obra sobre a gênese da França moderna, investigou essa conexão por todos os ângulos, expondo-a com grande maestria histórica. Para Taine, toda a Revolução Francesa não é nada além do amadurecimento do espírito clássico da filosofia francesa: aquele esprit classique, como se personifica nas obras de Montesquieu e Voltaire, Rousseau e Condorcet, Diderot e Holbach. Quando nos lembramos do profundo e abrangente efeito que irradiou especialmente da obra de Rousseau, essa conexão figura-se diante de nós, como que para ser nitidamente apreendida. A declaração francesa dos direitos dos homens e dos cidadãos significou, sobretudo, algo diferente de um selo, por assim dizer, que os acontecimentos reais e o mundo da realidade histórica imprimiram sobre as ideias fundamentais de Rousseau - foi a declaração francesa dos direitos dos homens e dos cidadãos algo distinto da transformação dos pensamentos rousseunianos em uma reinvindicação política e em um ato político peremptório? 0 homem, como o Deus da Bíblia”, assim se lê em Heine, em seu escrito Contribuições à história da religião e da filosofia na Alemanha,

precisa apenas exprimir seus pensamentos, e (...) faz-se luz ou escuridão, separamse as águas da terra, ou, até mesmo, criam-se bestas selvagens. 0 mundo é a manifestação da palavra. Isso vós também podeis perceber, orgulhosos homens de ação. Vós não sois nada além de serviçais involuntários dos homens de pensamento, os quais, frequentemente, em estilo humilde, têm direcionado da forma mais determinada possível todas as vossas atitudes. Maximilien Robespierre nada mais foi do que a mão de Jean-Jacques Rousseau, a mão sanguinária que tomou o corpo do ventre de sua própria época, cuja alma, entretanto, foi criada por Rousseau (Heine, 1910, p.294).

O que Heine expressa aqui na forma de uma engenhosa visão geral foi tido por muito tempo, dentro da ciência do direito constitucional, como uma verdade segura e amplamente aceita. Georg Jellinek $(1904)^{5}$ foi o primeiro a atacar - em um breve, porém penetrante e substancioso tratado sobre a declaração dos direitos dos homens e dos cidadãos - essa interpretação e o primeiro a negá-la em seu caráter axiomático. Jellinek apontou enfaticamente para o fato de que não existe harmonia entre o

4 Ver especialmente Taine, 1909, p.265-318.

5 Ver também a terceira edição organizada por Walter Jellinek com base nos manuscritos póstumos (Jellinek, 1919). 
universo de ideias do Contrato Social de Rousseau e o universo de ideias que cresceu a partir da declaração da Constituinte Francesa de 26 de agosto de 1789, mas sim uma oposição nítida e total. Isso porque em Rousseau o indivíduo é sacrificado no momento em que, através do contrato social, ele se apresenta juntamente com os demais, sem restrição, em favor da vontade da coletividade. 0 indivíduo renuncia a todos os seus direitos fundamentais - e precisamente essa renúncia caracteriza o princípio supremo da teoria rousseauniana do Estado. Todas as normas do contrato social podem ser remetidas a uma única, como Rousseau salienta explicitamente: "a alienação total à comunidade de cada um dos seus associados". Essa renúncia não conhece nenhum limite e nenhuma reserva: "se a alienação se faz sem reservas, a união é a mais perfeita possível, e nenhum associado tem alguma coisa a reclamar" (Rousseau, 1977, p.21). Portanto, a retrospecção em direção aos escritos de Rousseau - e do mesmo modo, como se deixa evidenciar, a retrospecção em direção a Montesquieu ou Voltaire - não é de modo algum suficiente para desvelar a verdadeira origem da reivindicação pelos direitos fundamentais e inalienáveis do indivíduo. Assim, devemos, com o intuito de retomar as fontes efetivas dessa reivindicação, seguir outro caminho, com efeito, um caminho longo e árduo. Transferimo-nos para o centro daquele grande movimento intelectual introduzido na Alemanha do século XVII por Leibniz. 0 que Leibniz realizou como pensador teórico, metafísico, lógico, matemático, e o que ele representou para o desenvolvimento de uma filosofia universal, uma filosofia europeia geral: não pode ser no presente momento discutido de maneira mais detalhada. Quanto mais o rico e vasto material dos arquivos em Hannover torna-se acessível, mais somos tomados por uma grande admiração pela amplitude e profundidade alcançadas por essas refinadas produções teóricas. Aliás, elas apenas correspondem a uma parte, a um momento específico da vida e atuação dessa mente universal. Seus esboços e memórias políticas são praticamente iguais, em sua própria amplitude, aos seus escritos filosóficos e matemáticos: e mais, eles estão também repletos de pensamentos fecundos e originais, de previsões e perspectivas geniais. Aqui, a teoria filosófica repousa, sobretudo, no profundo conhecimento de um genuíno homem de Estado; por toda parte se percebe em sua teoria filosófica a pulsação direta da vida histórica do tempo e seus latentes problemas políticos e sociais. Também a teoria do Estado de Leibniz encontra-se sob a máxima que direciona o conjunto de sua filosofia: sob o pressuposto de que entre o mundo do ideal e o mundo do real não pode haver um abismo intransponível; mas que ambos, em sua genuína harmonia, relacionam-se e interpenetram-se mutuamente. "o real não deixa de se governar (...) pelo ideal e abstrato" (Leibniz, 1859, p.93) - o verdadeiro ideal é o que, por fim, confere à realidade sua forma, imagem e afeição. Pois bem, Leibniz foi inclusive - pelo menos da forma que eu vejo - o primeiro dentre os grandes pensadores europeus a defender como fundamento de sua ética e de sua filosofia do direito e do Estado, com total 
vigor e com toda firmeza, o princípio dos direitos fundamentais e inalienáveis do indivíduo. Ele baseia-se aqui, sem dúvida, na Antiguidade, principalmente no modelo estoico, da mesma forma que Hugo Grotius, o fundador da teoria moderna do direito natural. Mas, por outro lado, todas essas correntes do pensamento foram unificadas por Leibniz em um novo centro e como que unidas sob um novo escopo intelectual. Já que para Leibniz a oposição entre individualismo e universalismo e a pergunta sobre a possibilidade de reconciliação entre ambos não constituem um problema isolado da filosofia do Estado; mas é o grande eixo-motriz comum que compenetra todos os elementos de sua filosofia e que a conecta a um cosmos intelectual homogêneo. Não seria possível aprofundar-me nesse contexto - com isso, contento-me em citar uma passagem dos escritos éticos e políticos de Leibniz, na qual essa reivindicação de determinados direitos fundamentais e inalienáveis do indivíduo expressa-se, talvez, da forma mais nítida e expressiva. Quando Leibniz, seguindo os princípios do direito natural, examina a pergunta da legitimidade da escravidão, ele chega à conclusão de que mesmo quando o direito de propriedade de um homem sobre o outro possa ser fundamentado de forma estritamente jurídica, o exercício desse direito há de se assentar sempre sobre delimitações precisas. Isso porque se apresenta aqui outro "direito estrito", de natureza mais sublime: o direto da alma racional, a qual é por natureza e por excelência, de forma inalienável, livre; o direito de Deus, o senhor supremo dos corpos e das almas, em cujo reino os senhores são concidadãos de seus criados, porque no reino de Deus senhores e servos usufruem o direito civil do mesmo modo. “Em vista disso, pode-se dizer”, assim Leibniz continua,

que o direito de propriedade sobre o corpo de um homem pertence exclusivamente à sua alma e o mesmo não pode lhe ser destituído, já que a alma não é uma possessão adquirível. Desta maneira, também a propriedade sobre o corpo de um homem não pode ser comprada. Assim, o direito que os senhores possuem sobre seus escravos nunca pode ser pensado como propriedade no sentido estrito do termo, mas sempre, apenas como uma espécie de usufruto. Todavia, todo usufruo tem seus limites: deve ser exercido salva re, isto é, de tal maneira que o objeto, sobre o qual se projeta, não sofra nenhum dano ou seja levado ao extermínio (Leibniz, 1885, p.79).

O princípio instituído por Leibniz e sobre o qual se sustenta sua interpretação do direito natural, experimentou seu aprimoramento e desenvolvimento pleno por meio de seu mais fiel discípulo, Christian Wolff. Wolff é, na acuidade especulativa e na força criativa do pensamento, de nenhuma forma comparável a Leibniz; todavia, seu inestimável valor histórico consistiu em ter sintetizado os feitos de Leibniz, os conservado e, por meio de um zeloso trabalho intelectual, os assegurado. Assim, ele pôde desempenhar no século XVIII a mesma função que coube a Melanchthon nos primeiros decênios da Reforma - desta forma, ele transforma-se em um verdadeiro praeceptor Germaniae. E essa meticulosidade é a mesma que distingue sua filosofia do direito e do Estado. O que em Leibniz foi apenas esboçado e disseminado de forma 
aforística, foi desenvolvido por Wolff na mais ampla exposição em seus volumosos trabalhos Jus naturae methodo scientifica pertractatum (1744) e Institutiones juris naturae et gentium (1750). 0 patrimônio intelectual de Leibniz é agora pela primeira vez, de fato, alçado e trazido à tona; o seu legado é transplantado para livros didáticos, manuais científicos e desmembrado em centenas de detalhados parágrafos. Somente por meio dessa transposição - a qual era efetivamente menos propícia à precisão, concisão e rigor do pensamento - a doutrina de Leibniz foi, por assim dizer, transformada em "moeda viável”. E aqui, nas obras de Wolff, encontra-se, por conseguinte, também o primeiro desenvolvimento sistemático pleno na filosofia mais recente a incorporar a ideia dos direitos natos e inalienáveis. Por direito nato (jus connatum) Wolff entende todo direito que deriva diretamente da essência do homem, de seu conceito e quididade; já por direito contratual (jura contracta) Wolff entende todo direito que em vez de se basear na essência do homem, fundamenta-se apenas em uma determinação acidental, apenas em uma condição casual e mutável. Fazem parte deste último tipo todos os privilégios e regalias particulares, como aqueles que os homens gozam em virtude de sua linhagem, posição etc. No âmbito dos legítimos direitos fundamentais terminam todas essas regalias. Aqui vale a máxima da absoluta igualdade dos sujeitos de direito. Ao lado do direito de igualdade tem-se, então, em segundo lugar, o direito de segurança pessoal, o jus securitatis, além disso: cabe a todo indivíduo o exercício despreocupado de todos os atos que consistem em sua subsistência física e seu aprimoramento como ente espiritual. 0 efeito contínuo desses pensamentos fundamentais de Christian Wolff pode ser encontrado na filosofia alemã do século XVIII por todo lado, embora esse efeito, de nenhum modo, tenha ficado restrito à Alemanha. Uma das mais importantes e mais influentes obras de teoria do Estado inglesa da época: o famoso Comentários sobre as leis da Inglaterra de Blackstone, publicado no ano de 1765, mostra, ao lado da influência de Locke, vestígios claros da influência wolffiana. E com isso, encontramo-nos, desde já, no ponto no qual a ideia dos direitos fundamentais inalienáveis do indivíduo alastra-se da esfera da teoria pura para o domínio da prática política. Visto que os comentários de Blackstone - os quais tiveram a mais ampla divulgação não apenas na Inglaterra, mas também na América - constituem o modelo teórico com base no qual as constituições foram criadas, aquelas que os Estados americanos autônomos após a independência da coroa inglesa instituíram para si. Essas declarations of right americanas ${ }^{6}$ - entre as quais se destaca a declaração do Estado Livre da Virgínia de 12 de junho de 1776,

\footnotetext{
6 Ver, sobretudo, o texto da declaração de direitos da Virgínia em Jellinek (1919, p.81 em diante). Também o trabalho mais recente sobre esse assunto (Salander, 1926); igualmente o artigo (Voegelin, 1929). O quão forte era consciente, na Assembleia Nacional Francesa, a própria dependência em relação às declarações norte-americanas, transluz-se nas declarações de Rabaut Saint-Étienne no debate de 18 de agosto: "É que, assim como os americanos, queremos nos regenerar; a declaração de direitos é, portanto, essencialmente necessária” (citado segundo: Voegelin, 1929, p.85).
} 
como a primeira e a mais importante - culminam, em conjunto, na ideia de que todos os homens são iguais, livres e independentes por natureza, e que esses são direitos intrínsecos e fundamentais dos homens, os quais não podem ser-lhes tirados por meio de sua entrada na sociedade organizada sob o Estado, direitos que eles mesmos jamais podem renunciar em nome de sua prole por força do vínculo. E agora, depois de termos percorrido todas as fases individuais do desenvolvimento da ideia dos direitos fundamentais do homem e do cidadão, encerram-se os contornos da reflexão. Estamos novamente no ponto do qual partimos. Portanto, depois das demonstrações pormenorizadas de Jellinek, as quais foram ainda ampliadas pela pesquisa posterior e apoiadas em sua essência, não pode restar nenhuma dúvida de que os Bills of Right $^{7}$ dos estados autônomos livres da América constituíram o modelo efetivo para a declaração da Assembleia Nacional de 26 de agosto de $1789 .{ }^{8}$ Passo a passo, não raras vezes, palavra por palavra, pode-se perceber essa influência. A alusão às declarações norte-americanas não são visíveis apenas em toda parte da literatura panfletária francesa da época; mas se encontra também nos, assim chamados, Cahiers de 1789 - isto é, encontramos seus vestígios nos documentos entregues aos deputados, nos quais os diferentes estados da França registraram suas queixas e reinvindicações. E, finalmente, os homens que na própria Assembleia Nacional exigiram a declaração dos direitos dos homens e dos cidadãos e registraram textualmente seu teor foram, praticamente sem exceção, convictos partidários e admiradores da constituição dos Estados livres americanos. Em primeira escala há de se nomear aqui como mediador de ideias e ativo apologista, Lafayette, o qual viajou ainda jovem à América e da forma mais gloriosa participou da grande luta pela liberdade. Em suas cartas e memórias, Lafayette classificou sua estadia na América e sua amizade com George Washington

\section{Declarações de direito. (N.T.)}

8 A documentação mais detalhada sobre a dependência da declaração da Assembleia Nacional Francesa em relação aos "Bills of Rights" norte-americanos encontra-se agora no trabalho (Klövekorn, 1921, p.129 em diante). A interpretação sustentada aqui, de que a origem, de fato, das ideias fundamentais das "Declarations of Rights" americanas devem ser procuradas, não nas concepções e reinvindicações religiosas, mas sim nas ideias filosóficas e do direito natural, sintoniza-se inteiramente, no essencial, com o resultado alcançado por Justus Hashagen em uma investigação em andamento sobre os antecedentes das declarações americanas particulares. "Desde sempre", assim resume Hashagen seus resultados, "os direitos humanos eram um ramo na velha árvore cinzenta do direito natural. Sob os fecundos ventos da Revolução, o viço imemorial do direito natural cresceu novamente de forma espontânea. Os elementos religiosos fundamentais internos eram na época já fortemente secularizados. De toda forma, nos tempos da Revolução Americana não se precisava mais de rodeios sobre a liberdade religiosa, com isso, aquele viço cresceu e trouxe elucidação. (...) Assim, os revolucionários formularam seus direitos não como meros direitos do povo americano ou inglês, mas, com auxílio do direito natural, de forma totalmente ampla, como direitos humanos. (...) As raízes desse direito natural norte-americano jazem, sobretudo, na teoria do direito natural profano-europeu, aperfeiçoada desde o fim da era das guerras religiosas, o que passou a ser, há muito tempo, o condutor habitual do movimento de independência. (...) Outras coisas também indicam que o direito natural era útil não apenas como argumento, mas também como principal motivo tanto no debate dos direitos humanos, quanto na formulação de seu conteúdo" (Hashagen, 1924, p.482-483; 485; 487). 
como a verdadeira escola de suas concepções políticas. Assim, foi também o primeiro a entrar na Assembleia Nacional com um projeto, já elaborado, da declaração dos direitos dos homens e dos cidadãos: com um projeto que abrangia em si todas as ideias bases fundamentais da posterior declaração definitiva, formulado em íntima conexão com o texto das constituições americanas.

Olhemos mais uma vez retrospectivamente do ponto em que estamos e deixemos desfilar diante de nossos olhos intelectuais o todo do desenvolvimento, como até aqui foi apresentado. Assim, mostra-se uma curiosa migração e metamorfose de ideias. Um espírito filosófico universal, um dos verdadeiros fundadores do universo do pensamento moderno europeu, é aquele que confere ao princípio dos direitos fundamentais e inalienáveis do indivíduo seu cunho fixo e determinado e que indica seu lugar dentro do sistema da filosofia. Ele não cria o conteúdo desse pensamento; uma vez que o mesmo já existia como patrimônio da Antiguidade, especialmente, da filosofia estoica e ética. Entretanto, a nova forma agora abrangida por esse pensamento; a redação e fundamentação sistemática que lhe foram propiciadas; foithe também assegurado, desde então, um novo efeito irradiante em todos os âmbitos do cosmos espiritual. $\mathrm{O}$ que foi compreendido por Leibniz como grande constructo político e filosófico ganhou, em seguida, subsistência e extensão, estabelecida e integralmente elaborada por meio de uma genuína natureza erudita alemã, Christian Wolff. Nos dias de hoje, muitos dos escritos de Wolff nos parecem antiquados, demasiadamente amplos e pedantes: entretanto, desse mesmo pedantismo deriva o espírito de exatidão e meticulosidade lógica. É como se a nova ideia de impacto mundial tivesse que permear a estreiteza, mas também o estilo contemplativo de uma câmara erudita alemã, a fim de obter sua completa precisão e, por assim dizer, sua solidez. E agora a ideia alcança amplas dimensões; visto que, no formato concedido por Wolff, produz efeito sobre a Inglaterra. Com isso, todavia, a ideia experimenta, novamente e ao mesmo tempo, uma transformação característica. Os Comentários sobre as leis da Inglaterra de Blackstone não são mais, como já diz o título, pensados de forma puramente abstrata ou geral: eles são escritos por um inglês e para ingleses. "para Blackstone", assim formulou Jellinek, "apesar de sua concepção base do direito natural, o indivíduo empossado de direitos jurídicos não é o homem (...) mas o súdito inglês" (Jellinek, 1919, p.40). Por toda parte entrevêse em suas deduções - ao que parece, absolutamente racionais - a reminiscência dos processos da história inglesa e dos problemas particulares de sua constituição. Esse círculo de reflexão somente é interrompido quando se muda outra vez seu cenário político e cultural, quando as ideias de Wolff e Blackstone são recepcionadas e proclamadas pelos jovens Estados livres da América do Norte. Agora elas são, de fato, novamente vistas e moldadas de forma universal: o indivíduo enquanto tal (every individual), a humanidade como um todo (all mankind) constitui o verdadeiro 
sujeito de direito para os direitos fundamentais e inalienáveis. E com isso, no que diz respeito a esses direitos, não apenas todas as barreiras de classe, como também todas as barreiras nacionais são demolidas e declaradas como nulas e sem validade. Nesse momento, a fagulha como que se alastra da América do Norte em direção à França e, quando aqui encontra um amontoado de material inflamável acumulado por séculos, transforma-se, consequentemente, em um grande incêndio de proporções mundiais. Por conseguinte, a ideia pura enquanto tal mostra ter perdido efetivamente sua força; não tem mais o poder de sujeitar e dominar os espíritos os quais invocou, mas deve fazer - assim parece - algo diferente, retirar de campo a profunda e crescente violência.

Não obstante, por outro lado, mobiliza-se então na Alemanha um novo movimento reacionário de cunho estritamente intelectual. Uma vez que a filosofia alemã, como representada em Kant, simplesmente não desejava de modo algum render-se às novas ondas de violência, as quais ela agora observa no mundo real; mesmo quando a filosofia se entrega, ela imprime, ao mesmo tempo, sua mais ardente crítica. E essa crítica foi tão forte como a simpatia pessoal de Kant pela grande ideia que viu corporificada na Revolução Francesa. Incorruptível e implacável, quando se tratou do julgamento sobre o subsequente desenrolar da Revolução. A partir dos princípios básicos de sua ética, Kant condenou incondicionalmente a execução do casal real e os atos do período do terror. Ele classificou a época do Comitê de Salvação Pública como era "de abertas ilegitimidades fomentadas por uma situação revolucionária e declaradas como legais” (Kant, 1922, p.149). Em todos esses enérgicos julgamentos de valor sobre os acontecimentos e atos particulares da Revolução Francesa algo permaneceu, entretanto, inabalável para Kant: a "confiança racional" na própria ideia de uma constituição republicana. A convulsão politica enquanto tal já não o assustava, nem the causava pavor. Kant, aliás, há muito a havia previsto. No escrito kantiano Ideia para uma história universal sob um ponto de vista cosmopolita, concebido no ano de 1784, ou seja, cinco anos antes da eclosão da Revolução, a obtenção de uma constituição interna perfeita - e para esse propósito, também externa - é designada como objetivo da história política da humanidade. "Ainda que este corpo estatal”, então Kant acrescenta,

\footnotetext{
exista agora apenas em rústico esboço, todavia, já começa a se mover simultaneamente um sentimento em todas as estruturas, em todas cuja conservação do todo está sedimentada. E, finalmente, isso concede a esperança de que depois de tantas revoluções e remodelações, isto, que a natureza tem por propósito supremo, está, circunstancialmente, por chegar: um estado geral cosmopolita como o núcleo em que estão desenvolvidas todas as tendências primordiais do gênero humano (Kant, 1913, p.163).
}

Portanto, apenas a repetição de sua própria reinvindicação inicial e não a influência 
dos acontecimentos mundiais determinou que Kant definisse, dez anos mais tarde, no escrito À paz perpétua, como primeiro artigo definitivo da paz perpétua o princípio de que a constituição civil de todos os Estados deveria ser republicana. Visto que tal constituição por si só equivale, de acordo com Kant, à ideia de um "contrato original" sobre o qual se deve basear, em última instância, toda a legislação jurídica de um povo. Aqui Kant ressalta que a legitimidade e transparência da constituição republicana não dependem da forma exterior de governo, mas unicamente do preceito legislativo, por assim dizer, da forma interna do conjunto do Estado. Esse preceito deve ser arranjado de forma tal que através do mesmo só possam ser sancionadas leis que sejam oriundas da vontade coletiva do conjunto do povo. Os súditos não devem ser vistos apenas como súditos, mas também, de igual forma, como cidadãos, isto quer dizer, como coparticipantes da vontade coletiva: "Porque isso é a pedra de toque $^{9}$ da legalidade de toda lei pública” (Kant, 1914b, p.434 em diante) ${ }^{10}$. Aqui, como Kant expressamente ressalta, não é de modo algum necessário pressupor o contrato social como um fato histórico, algo que deva ser provado como proveniente de um acontecimento remoto, que um povo em algum momento tenha que ter realizado tal ato. Antes, pelo contrário, o contrato social não é nada mais nada menos que uma ideia da razão, a qual, entretanto, tem sua indubitável realidade prática, a saber, imputar a todo legislador que não se pode exigir do conjunto do povo algo diferente daquilo que a coletividade possa, considerando suas exigências e máximas éticas, deliberar sobre si mesma. Observamos aqui como o movimento que perseguimos conduz novamente para seu ponto de partida, como esse movimento, por assim dizer, retorna à sua origem. A reivindicação dos direitos fundamentais emanou da esfera da ideia e, em seguida, efetivou-se somente ao longo de suas rupturas no reino da experiência, no reino da realidade histórica. Ora, aliás, essa realidade histórica e seus resultados retornam novamente ao mundo ideal da filosofia alemã, quando então se projeta do reino do ser para o reino do dever, quando caminha da posição de um fato histórico para um imperativo ético.

Existiram dois homens na Alemanha do século XVIII que não visualizaram - da eminente posição na qual se encontravam - os grandes acontecimentos históricouniversais da época meramente enquanto tais, enquanto simples fatos empíricos, mas procuraram, ao mesmo tempo, interpretá-los intelectualmente e compreendêlos simbolicamente. Ao lado de Kant, situa-se Goethe, o qual afirmou ter sempre enxergado os acontecimentos mundiais, seu próprio movimento e atuação, de forma simbólica. Todavia, a forma de observação simbólica de Goethe segue outra direção, distinta daquela de Kant. Senhoras e senhores, todos se recordam da famosa descrição de Goethe na Campanha na França, a forma como ele, diante da Batalha

9 Rocha siliciosa de cor escura utilizada para determinar a pureza de um metal. (N. T.) 10 Ver o escrito Kant, 1914a, p.380-381. 
de Valmy, sentiu e exprimiu a grande mudança mundial. "De hoje em diante”, assim disse aos que o acompanhavam, "irradia uma nova época da história universal e vós podeis dizer que estivestes lá" (Goethe, 1898, p.75). Nessa sentença professase o dom espiritual mais peculiar de Goethe: aquele dom que em certa ocasião ele descreveu a Eckermann como "fantasia para a veracidade do real" (Goethe, 1910, p.245). Foi esse dom que o colocou em condição de ampliar temporalmente o momento presente em que se encontrava e visualizar claramente os desdobramentos sucessivos, os quais deveriam estar atrelados. Isso é a simbologia do grande artista, para o qual se sobressai, de repente, do pano de fundo de uma experiência concreta imediata, um mundo de destinos dos homens e dos povos. "Isso", assim disse o próprio Goethe, "é a genuína simbologia na qual o peculiar representa o geral, não como sonho e sombras, mas como descoberta viva e instantânea do impenetrável" (Goethe, 1907, p.59). Essa forma de deixar o geral visível no peculiar é característica e determinante tanto para o Goethe poeta quanto para o Goethe investigador da natureza. Ao procurar compreender e explicar, dentro de um princípio, o conjunto de sua observação sobre a natureza e o mundo, o próprio Goethe considerava que todo o seu procedimento baseava-se sempre no método "dedutivo": "eu não descanso enquanto não encontrar um ponto conciso a partir do qual muito possa ser deduzido, ou antes, pelo contrário, a partir do qual muito possa livremente se produzir. Pesa contra mim o fato de que eu sempre procedo com empenho e receptividade, de forma cautelosa e fiel" (Goethe, 1893, p.63). ${ }^{11}$ Goethe encontrou tal "ponto conciso" nos acontecimentos políticos na Batalha de Valmy: subitamente, o presente imediato engravidou-se do futuro - praegnans futuri, como Leibniz gostava de definir. Assim, Goethe encontrou conservado na realidade histórica algo que, aliás, procurava na poética. Viu diante de si um "caso eminente", o qual estava ali como representante de muitos outros, o qual encerrava em si certa totalidade e reivindicava, portanto, tanto externa quanto internamente, certa unidade e universalidade.

A simbologia do pensador Kant, não obstante, segue outro caminho distinto daquele do Goethe artista e investigador da natureza. Sua simbologia não se mantém atrelada à sequência dos fenômenos, não repousa nas manifestações naturais ou históricas a fim de nessas capturar e expor sua própria diversidade e totalidade; mas remete o conjunto das manifestações ao seu fundamento original; permite-nos lançar o olhar para o inteligível a partir do mundo do concreto-sensível, do empírico-real. O inteligível é para Kant, aliás, nada senão o mundo da liberdade. Compreender os acontecimentos históricos de forma simbólica: isso significa elevá-los a outra ordem, distinta da causalidade da natureza; pensá-los não somente no reino da natureza, mas também como que simultaneamente pertencentes, no sentido mais primordial, ao reino da finalidade. $\mathrm{E}$, novamente, essa forma de pensar de Kant não se conserva

11 Ver Goethe, 1903, p. 243-247. 
em lugar algum de maneira tão clara, tão definida e tão característica, como em sua interpretação da Revolução Francesa. Para isso, basta citar uma única passagem que é tão significativa a ponto de estar incluída em um de seus últimos escritos, do ano de 1798, Disputa das faculdades. Mais uma vez Kant observa retrospectivamente, agora com 74 anos, o todo da Revolução Francesa: neste momento, não obstante, ela ocupa-o e captura-o não mais como algo imediatamente próximo, como efetivo acontecimento empírico. Aqui, Kant a impele em um distanciamento ideal a fim de compreendê-la e avaliá-la partindo desse olhar intelectual distanciado. Kant levanta novamente a questão que ocupou de forma mais interior e que moveu todo o conjunto da filosofia do século XVIII e da filosofia do iluminismo: está o gênero humano em constante progresso, em constante aprimoramento? Ele bem sabe e declara, com a mais exacerbada e crítica acrimônia, que a tal problema não se permite mais uma solução puramente empírica. Isso porque qualquer imersão nos nexos causais dos acontecimentos, no curso empírico dos dados naturais, não nos propicia elucidação alguma sobre o caminho que a humanidade enquanto sujeito "inteligível", enquanto sujeito de liberdade, pode e vai seguir. Entretanto, pode-se pensar, seguindo Kant, em outra relação indireta do empírico com o inteligível, do mundo da experiência histórica com o mundo da ideia moral. Do meio de uma série de acontecimentos empírico-históricos, sobressaem-se individualmente grandes eventos, dos quais o pensador, o observador filosófico, depreende indiretamente que eles não se limitam a uma sequência, mas que possuem um significado ético-universal. $E$ tal significado ético conciso é atribuído por Kant, sobretudo, à Revolução Francesa. Para Kant a Revolução pode ser tida como o evento da história contemporânea que demonstra de maneira mais explícita e mais convincente a "tendência moral do gênero humano".

Essencialmente, esse evento não consiste em atos e barbáries humanas por meio dos quais se tornou pequeno o que era grande e tornou-se grande o que era pequeno. Como que através de um passe de mágica se desvanecessem antigos e esplêndidos edifícios estatais e surgissem outros no lugar, como que oriundos das profundezas da Terra. Não: nada disso. (...) A revolução de um povo rico intelectualmente, a revolução que visualizamos desenrolar em nossos dias, seja exitosa ou malograda, pode resultar em miséria e atos atrozes de forma que um homem efetivamente ilustrado, caso pudesse realizar a revolução diligentemente e com alegria, jamais deliberaria o experimento com tais custos - eu digo, aliás, que essa revolução encontra-se nas almas de todos os espectadores (...) uma participação da vontade que beira o entusiasmo (...) não é mais possível esquecer tal fenômeno da história da humanidade, pois ele revelou uma tendência e uma potencialidade na natureza humana para o melhor. Algo que nenhum político captou no desenrolar das coisas até o presente momento, que apenas natureza e liberdade estão unidas no gênero humano por meio de princípios de direito intrínsecos (...) se a finalidade pretendida por esse evento também não for alcançada agora, se, porventura, no final a revolução ou reforma da constituição de um povo fracassar, ou se depois de se conceder a essas algum tempo, tudo for reconduzido para o rumo anterior (como políticos agora auguram), mesmo assim, aquela previsão filosófica não perde nada de sua força. 


\begin{abstract}
Porque aquele evento é tão grandioso, tão fortemente entrelaçado com o interesse da humanidade e sua influência tão disseminada por todas as partes do mundo, que ele não é trazido à memória dos povos por quaisquer circunstâncias favoráveis que deveria induzir a repetição de novas tentativas dessa natureza; porque, consequentemente, em um assunto tão importante para o gênero humano, a pretendida constituição deve, finalmente, alcançar a qualquer momento aquela solidez, a qual não careceria de instrução uma vez que já se encontra estampada na alma de todos por meio da repetida experiência (Kant, 1916, p. 397-398; 401).
\end{abstract}

Nessas frases apresenta-se da forma mais simples e mais clara aquela forma de reflexão simbólica que distingue Kant, o filósofo idealista e ético. Ele não pergunta, o que segue imediatamente um ato na sequência dos acontecimentos reais, mas ele indaga, de quais fundamentos intelectuais e morais o ato deriva; a fim de julgá-lo, Kant não olha para seu resultado, mas para seu motivo moral, para as "máximas" que o fundamentam, para o direcionamento dos ânimos que ele fomenta. Pode-se indeferir a essa máxima sucesso externo, mesmo assim não se modifica o seu teor e o seu valor: isso porque o parâmetro para o seu valor não jaz no que é alcançado através de um ato, no que é trazido através dele de forma imediata ao mundo da realidade empírica, mas na forma normativa sob a qual a máxima se estabelece e que procura personificar em si.

Permitam-me, senhoras e senhores, finalizar esta reflexão. Que eu de um ponto de vista estritamente científico não exauri completamente o tema a que me propus, que eu apenas o esbocei em poucas características, apenas de maneira fragmentária e imperfeita: disso estou plenamente consciente. Entretanto, o sentido das comemorações do dia de hoje também não pode ser de que nos aprofundemos cientificamente em um problema meramente histórico ou meramente filosófico. As minhas reflexões pretenderam apresentar aos senhores o fato de que a ideia de uma constituição republicana enquanto tal não é de forma alguma desconhecida nem sequer intrusa no conjunto da história alemã, antes, pelo contrário, ela foi desenvolvida em seu próprio solo e nutrida por meio de suas forças mais peculiares, por meio das forças da filosofia idealista. Todavia, também esse conhecimento histórico permaneceria infrutífero e sem efetividade se desejássemos compreendê-lo pura e simplesmente como um saber sobre o passado, sobre acontecimentos e coisas sem importância. "O melhor que temos da história”, diz Goethe, "é o entusiasmo que ela suscita" (Goethe, 1907, p.173). Assim, o aprofundamento na história da ideia de constituição republicana também não deve estar simplesmente voltado ao passado, mas deve fortalecer em nós a crença e a confiança de que as forças, a partir das quais a ideia de constituição republicana foi originalmente desenvolvida, também indicarão no futuro o caminho e que a constituição republicana, por sua vez, ajudará a conduzir esse futuro. 


\section{Referências}

Borries, K. (1928). Kant als Politiker: Zur Staats- und Gesellschaftslehre des Kritizismus. Leipzig: Meiner.

Goethe, J. W. (1891). Zur Morphologie: Teil 1. Weimar: Böhlau. (Weimarer Ausgabe $\mathrm{VI})$

$\mathrm{XI})$

(1893). Zur Naturwissenschaft. Weimar: Böhlau. (Weimarer Ausgabe

(1898). Campagne in Frankreich 1792. Weimar: Böhlau. (Weimarer Ausgabe XXXIII)

. (1903). Goethes Briefe 1797. Weimar: Böhlau. (Weimarer Ausgabe XII)

(1907). Maximen und Reflexionen über Literatur und Ethik. Weimar:

Böhlau. (Weimarer Ausgabe XLII)

. (1910). Zu Johann Peter Eckermann, 25. Dezember 1825. In Biedermann, F. (org.). Goethes Gespräche (pp. 244-247). Leipzig: Biedermann. (Gesamtausgabe III)

Hashagen, J. (1924). Zur Entstehungsgeschichte der nordamerikanischen Erklärungen der Menschenrechte. Zeitschrift für die gesamte Staatswissenschaft, 78, pp. 461-495.

Heine, H. (1910). Zur Geschichte der Religion und Philosophie in Deutschland. In: Sämtliche Werke VII (pp. 185-354). Leipzig: Insel.

Jellinek, G. (1904). Die Erklärung der Menschen- und Bürgerrechte: ein Beitrag zur modernen Verfassungsgeschichte. 2ed. Leipzig: Duncker \& Humblot.

. (1919). Die Erklärung der Menschen - und Bürgerrechte: ein Beitrag zur modernen Verfassungsgeschichte. 3ed. München, Leipzig: Duncker \& Humblot.

Kant, I. (1913). Idee zu einer allgemeinen Geschichte in weltbürgerlicher Absicht. In: Buchenau, A.; Cassirer, E. (orgs.). Immanuel Kants Werke IV (pp. 149-166). Berlin: Bruno Cassirer.

- (1914a). Über den Gemeinspruch: Das mag in der Theorie richtig sein, taugt aber nicht für die Praxis. In: Buchenau, A.; Cassirer, E.; Kellermann, B. (orgs.). Immanuel Kants Werke VI (pp. 355-398). Berlin: Bruno Cassirer.

. (1914b). Zum ewigen Frieden: ein philosophischer Entwurf (1795). In: Buchenau, A.; Cassirer, E.; Kellermann, B. (orgs.). Immanuel Kants Werke VI (pp. 425-474). Berlin: Bruno Cassirer.

. (1916). Der Streit der Fakultäten. In: Kellermann, B. (org.). Immanuel Kants Werke VII (pp. 311-431). Berlin: Bruno Cassirer.

(1922). Anthropologie in pragmatischer Hinsicht. In: Schönderffer, O. (org.). Immanuel Kants Werke VIII (pp. 1-228). Berlin: Bruno Cassirer.

Klövekorn, F. (1921). Die Entstehung der Erklärung der Menschen- und Bürgerrechte. Berlin: Ebering. (Historische Studien 90)

Leibniz, G. W. (1859). Brief an Pierre Varignon vom 2. Februar 1702. In: Gerhardt, C. I. (org.). Mathematische Schriften IV (pp. 91-95). Halle: Schmidt. 
- (1885). Méditation sur la notion commune de la justice. In: Mollat, G. (org.). Rechtsphilosophisches aus Leibnizens ungedruckten Schriften (pp. 5681). Leipzig: Robolsky.

Metzger, J. D. (1804). Aeußerungen über Kant: seinen Charakter und seine Meinungen. Königsberg: Göbbels und Unzer.

Rousseau, J-J. (1977). Do contrato social. Tradução de Mário Franco Nogueira. Lisboa: Presença.

Salander, G. A. (1926). Vom Werden der Menschenrechte: Ein Beitrag zur modernen Verfassungsgeschichte unter Zugrundelegung der virginischen Erklärung der Rechte vom 12. Juni 1776. Leipzig: Weicher.

Taine, H. (1909). Les origines de la France contemporaine. Volume 1: L'ancien régime. 27ed. Paris: Hachette.

Voegelin, E. (1929). Der Sinn der Erklärung der Menschen - und Bürgerrechte von 1789. Zeitschrift für öffentliches Recht, 8, pp. 82-120.

Vorländer, K. (1911). Immanuel Kants Leben. Leipzig: Felix Meiner.

(1912). Kants Stellung zur französischen Revolution. In: Philosophische Abhandlungen: Hermann Cohen zum 70sten Geburtstag (4. Juli 1912) Dargebracht (pp. 247-269). Berlin: Bruno Cassirer.

Recebido em: 06.12.2017

Aceito em: 10.05.2018 